\title{
NuEVAS CORRIENTES EN FILOSOFÍA DE LA RELIGIÓN
}

No me propongo elaborar una defensa de la religión, así como tampoco sumarme a los ataques de los que ha sido objeto desde muy diversos horizontes. No voy a referirme a una religión en particular, como sería el catolicismo, entre nosotros todavía mayoritario, o de manera más general al cristianismo, aunque buena parte de las observaciones que ofrezca tengan que ver sobre todo con las doctrinas y la prácticas religiosas provenientes de la tradición o de la teología cristianas, que son para mí las más familiares.

El motivo que me ha llevado a elaborar estas consideraciones sobre la filosofía de la religión proviene de una vieja curiosidad que me acompaña, al percibir la profunda y acelerada transformación de la religiosidad en nuestra sociedad colombiana, ya que considero que dichos cambios son, por una parte, la consecuencia de profundas transformaciones en nuestra sociedad, a la vez que, por otra, contribuyen de manera muy profunda y significativa a la aceleración de esos mismos cambios. De ahí que comprenderlos en su verdadera significación constituya un paso necesario para entendernos y evaluarnos de manera acertada. Es cierto que la 
academia comienza a percatarse de ello, y cada día vemos aparecer nuevos estudios que, desde la historia, la sociología o la antropología, buscan examinarlos y comprenderlos. Sin embargo, en el campo de la filosofía son todavía muy escasos los esfuerzos que se hacen en este sentido. Es cierto que la clásica apologética elaborada por el catolicismo con el propósito de defenderse como religión oficial, así como el correspondiente anticlericalismo no menos unilateral, han cedido el paso a posiciones menos antagónicas entre quienes se interesan por el fenómeno religioso, y cada vez el esfuerzo reflexivo se orienta a comprender mejor el fenómeno antes de proceder a enjuiciarlo. Pero no es fácil encontrar, dentro de la producción filosófica en Colombia, reflexiones que se propongan presentar y elaborar las nuevas condiciones bajo la cuales se lleva a cabo, en otros horizontes, la reflexión filosófica sobre lo religioso ${ }^{1}$.

Ahora bien, si tenemos en cuenta el importante papel que ha jugado en nuestra historia y en nuestra cultura la religión en general, y la religión católica en particular, y si pensamos, además, en el hondo significado que en todas las culturas ha tenido la religión, tenemos que aceptar que se trata de un tema que debería suscitar un interés particular para la reflexión filosófica. Después de todo, la religión es a la vez un reflejo de la manera como una sociedad se comprende, y un elemento que determina, como el que más, esa misma comprensión.

Pero si esta preocupación por la importancia que tiene el fenómeno religioso para comprender la idiosincrasia de un pueblo y por las transformaciones a las que se ve confrontado ha sido la razón principal de mi interés para incursionar en el terreno de la filosofía de la religión, en esta ocasión no me voy a orientar propiamente en ese sentido. No pretendo profundizar en el significado que puedan tener las transformaciones que ha sufrido la religiosidad de nuestra sociedad, ni examinar el papel que esos cambios hayan podido jugar en la configuración de nuestra dinámica social. De manera bastante más específica, y restringiéndome al campo de la filosofía, mi propósito es mostrar cómo la religión está volviendo a ser objeto de acentuado interés filosófico, aunque entre nosotros el tema pareciera estar todavía muy ausente de nuestras preocupaciones académicas. Me propongo señalar la manera como la religión está siendo

1 En los últimos años, este interés por el fenómeno religioso en sus diversas manifestaciones ha ido creciendo. 
analizada por parte de algunos filósofos contemporáneos, provenientes sobre todo del campo de la llamada filosofía analítica -nombre, por lo demás, cuyo contorno se ha ido desdibujando cada vez más-, así como los principales temas que concitan el interés de la polémica.

Pero antes de entrar a examinar el tema propiamente tal, considero necesario avanzar algunas consideraciones preliminares que me permitan situar el asunto dentro de un horizonte más amplio.

\section{La filosofía de la religión: fenómeno moderno}

En primer lugar, es importante tener en cuenta que la filosofía de la religión es un fenómeno propio del pensamiento moderno. Es cierto que desde los inicios mismos del cristianismo, y a todo lo largo del Medioevo, se llevaron a cabo discusiones y controversias, y se presentaron propuestas muy diferentes para determinar el puesto de la religión frente a las pretensiones de la razón. Las relaciones entre razón y religión fueron motivo de constante preocupación desde los primeros siglos del cristianismo para los así llamados 'Padres de la Iglesia', pero las raíces de tal preocupación llegan hasta el judaísmo en su encuentro con la cultura griega, como en el caso de Filón de Alejandría ( \pm 20 a. C. - 40 d. C.). Precisamente, una de las características del cristianismo, presente ya en los pensadores judíos, fue el deseo de confrontar sus doctrinas con lo enseñado por los pensadores paganos, y de buscar ya sea una concordancia, ya sea una delimitación precisa de sus respectivos ámbitos y competencias. Mientras que algunos pensadores cristianos sostuvieron que la filosofía venía a ser una suerte de preparación a la doctrina revelada, otros, en cambio, buscaron apartar a los creyentes de los peligros que significaban para la fe las doctrinas filosóficas paganas. Entre estos extremos se han presentado y se siguen presentando toda suerte de alternativas.

Fue durante el siglo XIII, al llegar la escolástica a su madurez, cuando los teólogos, siguiendo a Tomás de Aquino, precisaron con claridad que filosofía y teología constituían campos diferentes aunque conectados, pero poseedores cada uno de su relativa autonomía. Relativa, porque mientras que la teología no podía pretender desarrollarse sin la ayuda de la razón, la filosofía no podía pretender ser la única capaz de encontrar la verdad y de señalarle al hombre las normas para su comportamiento. 
Esta suerte de amalgama o de compromiso entre religión y filosofía, o entre fe y razón, ha vuelto a ser objeto en nuestros días de fuertes controversias. En el seno de la teología cristiana, se ha llegado a preguntar si con ello no se ha puesto en cuestión la esencia misma del mensaje religioso, como si para ser creyente hubiera que someterse previamente a los cánones de la cultura occidental de origen griego. Se ha hablado así de la 'helenización' del cristianismo. Sin embargo, una figura tan significativa para el catolicismo como lo es hoy el otrora teólogo y pontífice, Joseph Ratzinger, considera que "el encuentro entre la fe de la Biblia y la filosofía griega fue verdaderamente providencial" (p. 85). Con lo cual parece decir que esa amalgama o compromiso entre fe y razón ha venido a formar parte del núcleo mismo del mensaje cristiano.

Ese largo y complejo proceso de confrontación, uno de cuyos mayores resultados ha venido a ser precisamente el pensamiento moderno, tuvo a su servicio a los mejores talentos de la cristiandad, de modo que no resulta posible comprender a cabalidad, no solo la modernidad como tal, sino toda la historia de la cultura occidental, sin tenerlo en cuenta en su rica complejidad. No me parece para nada descabellado leer la historia de Occidente como lo ha hecho Richard Kroner, viéndola como una lucha sin cuartel entre dos espíritus contrapuestos: la religiosidad piadosa y moralista de raíces judías, y la racionalidad estética y humanista de los griegos, "la Antigüedad y el Cristianismo" (Kroner, 1977, p. 255 y ss.). Esta confrontación, nos dice, ha tenido a lo largo de la historia de Occidente dos momentos culminantes. El primero, cuando Tomás de Aquino, en el siglo XIII, logró elaborar la gran síntesis de aristotelismo y cristianismo que es la Summa Theologiae, en la cual el espíritu racionalista griego vino a imponerse sobre el espíritu religioso de origen judío. Y el segundo momento culminante lo ve Kroner en G. W. F. Hegel, al pretender integrar de manera completa la teología, como reflexión racional sobre el mensaje revelado, y la filosofía, como la verdadera comprensión de dicho mensaje.

Sin embargo, para los pensadores medievales cuyo punto de partida eran las verdades que ofrecía la religión, no solo porque esas verdades tenían su origen en la palabra revelada por Dios, sino también porque incidían, de manera definitiva, en la tarea más importante de la vida humana, a saber, "el negocio de la salvación”, la idea de una filosofía de la 
religión hubiera resultado descabellada. Como bien lo ha indicado Pierre Hadot, el cristianismo tomó a su cargo la tarea, reservada en Grecia a la filosofía, de orientar al hombre en su paso por el mundo (cf. Hadot, 1955, p. 355 y ss.). Permitirle a la razón que juzgara la religión hubiera significado aceptarle la osadía inaudita de pretender constituirse en juez de la misma palabra divina. La sierva juzgando a su señora. Porque una filosofía de la religión viene a significar, en alguna forma, someter el mensaje revelado al tribunal de la razón.

Fue entonces necesario que la razón humana reconquistara, paso a paso, su plena autonomía, para que la idea de una filosofía de la religión pudiera abrirse camino. Solo entonces pudo considerarse aceptable que la razón tomara como objeto de su consideración las pretensiones de la religión revelada, y procediera a establecerle sus condiciones para justificar su sentido.

Esta función la ha venido ejerciendo la razón de maneras muy diversas. La filosofía ha examinado el fenómeno religioso y ha buscado comprenderlo, una veces para sustentarlo y defenderlo, otras para criticarlo como forma equivocada o ilusoria de conocimiento, y otras para delimitar sus aspiraciones y señalarle sus límites. Sin embargo, cabe decir que la gran mayoría de filósofos de la modernidad mantuvieron, dentro del conjunto de sus consideraciones sistemáticas, elementos que pueden considerarse religiosos. No en vano la metafísica ha sido calificada por Heidegger con el nombre, más crítico que honroso, de "onto-teo-logía”. Un caso particularmente significativo es el de Baruch Spinoza. Pocos como él se han interesado tanto por examinar el concepto de Dios y precisar sus contornos para establecerlo como pilar fundamental de su doctrina, y pocos como él han provocado mayor rechazo entre los creyentes por sus tesis heterodoxas. Aunque, como lo ha señalado Lelio Fernández, "Baruch Spinoza no toma en falso el nombre de su Dios" (2007); sin embargo, la identificación que lleva a cabo entre Dios y la naturaleza hace que su concepción resulte incompatible, para la teología cristiana, con el "Dios de Abraham, de Isaac y de Jacob". 


\section{Las críticas a la religión}

No es mi propósito entrar a considerar el puesto que le fuera otorgado a la religión en el desarrollo de la filosofía moderna. Pero sí cabe señalar que este desarrollo vino a desembocar en tres graves y profundas críticas, cuyas consecuencias resultan innegables en el tratamiento que se le ha dado a la religión, al menos dentro de la que ha sido llamada, hasta hace algunos años, la 'filosofía continental'. En primer lugar, el ataque acervo de F. Nietzsche contra el cristianismo, culpándolo de elaborar una moral enemiga de la vida; luego, la elaboraciones psicológicas de S. Freud, que sitúan el origen de lo religioso en los entresijos de nuestro complejo mundo inconsciente; finalmente, los análisis de K. Marx para descubrir los mecanismos alienantes de la religión, que han servido para encubrir las injusticias sociales e inhibir los mecanismos de su corrección.

A estas críticas se unieron muchas otras que, de una forma u otra, han desarrollado las tesis contenidas en estos tres pensadores. Como resultado de tales críticas, la religión fue perdiendo interés como objeto de reflexión filosófica, de modo que durante gran parte del siglo XX el tema de la religión se fue viendo relegado a un segundo plano, considerado cada vez más como un fenómeno cultural en vías de extinción que como un objeto digno de interés para la reflexión filosófica.

Es cierto que pensadores como M. Heidegger o K. Jaspers le dedicaron su atención, y que, en el campo católico, filósofos como G. Marcel, X. Zubiri o el jesuita B. Lonergan realizaron considerables esfuerzos para pensar la religión dentro de las condiciones establecidas por la filosofía moderna. Pero, como lo ha señalado muy bien Enrique Romerales:

Ni la fenomenología, ni el existencialismo, ni la Escuela de Frankfurt, ni el Círculo de Viena -y demás positivistas lógicos-, ni el estructuralismo, ni la hermenéutica, ni el postmodernismo -y creo no dejar ninguna corriente europea continental creadora de este siglo (XX)-, se han ocupado como tal de cuestiones religiosas, mucho menos teológicas, aunque sí algunos de sus componentes a título individual, y a menudo para dar una respuesta negativa (caso de Adorno, Carnap, Sartre, Albert). (1992, p. 12)2.

2 Romerales, en quien me apoyo para muchas de mis reflexiones, ha recopilado una excelente antología de textos sobre la religión (ver Bibliografía). 
Ahora bien, si éste ha sido el panorama general de la llamada 'filosofía continental', es decir, de la que se desarrolló en Europa continental al margen de las corrientes analíticas que florecieron en Inglaterra y en el ámbito anglosajón, en éste último la situación fue un tanto diferente. Allí pareciera como si los ataques contra la religión que conmovieron al pensamiento filosófico continental no hubieran tenido el mismo eco. Fue más bien a partir de lo que Alfred Ayer denominó "la ruptura con Hegel” (Ayer, 1982, p. 33 y ss.), llevada a cabo por Bertrand Russell, y por la filosofía del sentido común promovida por George E. Moore, como tuvo lugar el distanciamiento frente a la religión. Más que de un rechazo o de una crítica, se trató de una pérdida de interés llevada a cabo dentro del más exquisito estilo de D. Hume. Por ello, nos dice Romerales, "mientras en Europa [continental] el abandono de las cuestiones teológicas se hacía a menudo en nombre de la libertad de la metafísica, en el Reino Unido iban de la mano la condena de la teología y la de la metafísica, lo que convirtió a éstas en aliadas frente al enemigo común" (p. 14). Esto puede explicar, en parte, el hecho de que el interés por la filosofía de la religión haya surgido y se haya desarrollado con mucha mayor fuerza en el ámbito de influencia de la tradición analítica.

Por otra parte, mientras que el interés por la religión declinaba en el seno de la comunidad filosófica, la teología cristiana realizaba grandes esfuerzos para elaborar, desde su propio horizonte, temas religiosos de indudable carácter filosófico. El siglo XX vio florecer toda una generación de grandes teólogos, tanto en el campo protestante como en el católico. En el primero se han destacado figuras como Rudolf Bultmann, Karl Barth, Dietrich Bonhoeffer o Paul Tillich, y en el segundo, Urs von Balthasar, Karl Rahner o Hans Küng, para citar solo algunos de los más conocidos.

\section{La racionalidad de la religión}

Si nos propusiéramos recoger bajo un solo título las múltiples y muy variadas controversias que se han tejido alrededor de la religión por parte de la filosofía, podríamos decir que su común denominador lo constituye la pregunta: ¿es racional la religión?, ¿puede una persona que busca orientar su vida a la luz de la razón seguir creyendo lo que la religión le exige que crea? 
Aunque esta pregunta podría tener diferentes respuestas de acuerdo con las diversas religiones en cuestión, resulta lícito partir para su consideración de que las religiones en general configuran, en una u otra forma, un tejido de convicciones alrededor de la creencia en un Dios de características específicas. Esta afirmación podría prestarse a críticas, señalando, por ejemplo, el caso de algunas ramas del budismo donde se expone y se practica una suerte de ateísmo religioso o de religiosidad sin Dios.

En general, la pregunta acerca de la posibilidad de una religión o de una religiosidad sin Dios es objeto de controversia. Así, por ejemplo, Ernst Tugendhat ha señalado una diferencia entre religión y mística, que en gran medida se compagina con la utilizada por el teólogo Joseph Ratzinger para caracterizar el fenómeno religioso. En una y otra se trata de la actitud del ser humano ante lo sublime, pero mientras que en la religión objetiva eso sublime es un ser de carácter personal a quien llama Dios, la mística lo comprende como "algo que está más allá de nosotros - dice Tugendhat-y en relación con lo cual nos entendemos como pequeños" (2001, p. 20), pero sin que tenga en realidad un carácter divino.

En todo caso, la cuestión “¿es razonable la religión?” puede tomarse en, al menos, tres sentidos diferentes:

a. En primer lugar, la pregunta puede tener un sentido restringido y referirse a la coherencia interna del conjunto de creencias que se tejen alrededor de la fe en un Dios, según la manera como lo determina cada religión. Esta "racionalidad mínima”, como la denomina Romerales, suele ser reconocida por la mayoría de los filósofos de la religión, solo es puesta en cuestión por algunos ateos más estrictos. Tal es el caso, por ejemplo, de Anthony Flew o de Kai Nielsen. Este último considera que los enunciados religiosos conllevan necesariamente aserciones acerca de Dios y de su relación con los hombres y con el mundo, cuya inteligibilidad o coherencia no puede establecerse. Más aún, cuando de alguna forma esa inteligibilidad logra hacerse clara, tales aserciones resultan, por completo, contrarias a los hechos.

b. Pero si la pregunta por la racionalidad del teísmo puede tener ese sentido restringido, también es posible entenderla en un sentido más 
amplio. En este caso se trataría de preguntar: ¿son consistentes las creencias religiosas con el resto de creencias por lo general aceptadas por una sociedad dada, o por los intelectuales de dicha sociedad? Si se la plantea en esta forma más amplia, la cuestión misma sobre la racionalidad presenta serios problemas. No solo porque resulta muy difícil, si no imposible, establecer con precisión suficiente cuál sea ese conjunto de convicciones compartidas por una sociedad determinada, sino porque no se ve cómo tal conjunto, en caso de que pudiera ser establecido, estuviera en condiciones de convertirse en piedra de toque para evaluar la racionalidad o irracionalidad del teísmo.

c. Ahora bien, ante la dificultad que puede significar el establecimiento de la racionalidad o irracionalidad de las creencias religiosas, cabría entonces preguntar si son, al menos, razonables. Esta pregunta parece a primera vista más concreta: ¿resulta razonable creer?, ¿puede considerarse razonable que una persona cultivada acepte el teísmo y rija su conducta por las consecuencias que dicta su religión? En este último caso cabe todavía distinguir diferentes sentidos de la pregunta. Porque razonable puede significar, en forma muy débil, que una creencia no se muestre claramente absurda o altamente improbable. Entendida así, no suele haber dificultad en concederle al teísmo esta clase de razonabilidad, aunque tampoco faltan quienes la impugnen. Tal es el caso de J. Mackie, para quien el teísmo presenta un grado tan alto de improbabilidad, que su supervivencia resulta un verdadero milagro (Mackie, 1982, pp. 251-252).

Conviene señalar que, dentro de la tradición cristiana, la teología calvinista ha tendido con frecuencia a acentuar el carácter arracional o antirracional de la fe cristiana, como condición para una verdadera fe. Porque se considera que la fe solo puede llegar a ser un verdadero acto de confianza en la palabra de Dios, si aquello que tal palabra afirma no se muestra verosímil. Se trata de acentuar lo que tradicionalmente se ha llamado la fe fiducial, es decir, la fe como acto de confianza en una palabra dada, en contraposición con la fe dogmática como aceptación de ciertas y determinadas doctrinas. Más que aceptar el contenido semántico de unas aserciones, el énfasis se coloca sobre la confianza en la palabra de quien las ha expresado. El credo quia absurdum ('Creo porque es absurdo') de 
S. Kierkegaard es, precisamente, un caso extremo de esta tendencia, y es también el eco de un antirracionalismo cuyas raíces llegan hasta el siglo II de nuestra era. Ya entonces Tertuliano había escrito: "El Hijo de Dios ha sido crucificado; no me avergüenzo de ello, porque hay que avergonzarse. Y que el Hijo de Dios haya muerto es completamente creíble, porque es absurdo. Y que, enterrado, haya resucitado, es cosa cierta, porque es imposible" (De carne Christi, V, citado por Gilson, 1976, p. 93). Sin embargo, no parece correcto interpretar este juego retórico como una afirmación del carácter irracional de la fe religiosa.

Ahora bien, en total discrepancia con ese antirracionalismo, muchos defensores del teísmo consideran que no es suficiente, para justificar la creencia religiosa, el que se le reconozca esa clase de razonabilidad débil, es decir, que no se muestre como absurda o altamente improbable. Creen estar en condiciones de presentar argumentos que, si bien no pueden demostrar la necesidad racional de aceptar el teísmo, sí muestran que su probabilidad es mayor que la del ateísmo. Es el caso, por ejemplo, del teólogo y también filósofo Hans Küng, cuya defensa se propone equilibrar los argumentos en pro y en contra, de modo que resulta, al menos, tan razonable aceptarlo como rechazarlo. En realidad, Küng considera que los argumentos en pro son más convincentes, de modo que el teísmo sería más razonable que su contrario. Otro tanto sostiene R. Swinburne, siguiendo en ello la línea que había sido trazada por Tomás de Aquino, y contra la que se rebeló duramente el franciscano Guillermo de Ockham.

En contra de esta pretensión de razonabilidad fuerte, y en particular contra los argumentos de $\mathrm{H}$. Küng, Hans Albert ha desarrollado una aguda crítica, en un escrito cuyo título resulta de por sí muy diciente: La miseria de la teología. Albert se propone desarticular las pretensiones dogmáticas del cristianismo, y propugnar por lo que él llama la "etización” de la religión, es decir, la idea de convertirla en un conjunto de normas de conducta sin ningún fundamento teísta, en el mismo sentido en que lo propugnara en su momento Albert Schweitzer.

Ahora bien, si le exigimos al teísmo que demuestre ser razonable, no solo en el sentido débil de no ser altamente improbable o en el sentido más fuerte de ser tan probable como su contrario, sino de poseer un grado tal de razonabilidad que resulte claramente más probable que el ateísmo, un 
gran número de filósofos de la religión, así como de teólogos, estarían de acuerdo en que tal exigencia no puede ser cumplida y que tal vez tampoco deba serlo. En este caso, lo que cabría preguntar es si tan alto grado de probabilidad es necesario para que una creencia pueda ser aceptada de manera razonable. En la vida ordinaria solemos aceptar muchas creencias con un grado bastante menor de razonabilidad.

En la discusión de estos temas, el problema para los teólogos cristianos se deriva del conocido texto de Pablo en la Epístola a los Romanos, en el que buena parte de la tradición cristiana ha creído leer que la razón humana por sus solas fuerzas está en condiciones de conocer la existencia de Dios y sus atributos fundamentales. Recordemos el texto de Pablo:

En efecto, la ira de Dios se revela desde el cielo contra toda impiedad e injusticia de los seres humanos que aprisionan la verdad en injusticia, porque lo que se puede saber de Dios les está manifiesto, ya que Dios se lo ha manifestado. Porque lo invisible suyo, o sea, su fuerza eterna y su divinidad, es evidente a la inteligencia desde la creación del mundo por sus obras, de tal modo que son inexcusables, porque conociendo a Dios no le dieron gloria ni agradecimiento como a Dios, sino que se hicieron vanos en sus pensamientos y se oscureció su corazón insensato. (Rom. 1: 18-21).

Para los teólogos católicos, el problema se complica aún más, ya que tanto el Concilio Vaticano I, del año 1870, como el Papa Pío X, en 1910, determinaron, con toda claridad, que era doctrina profesada por la Iglesia Católica la capacidad de la razón humana para conocer la existencia de Dios y sus principales atributos. El texto del Concilio dice: "La misma Santa Madre Iglesia sostiene y enseña que Dios, principio y fin de todas las cosas, puede ser conocido por la luz natural de la razón humana a partir de las cosas creadas" (Denzinger y Schönmetzer, 1965, p. 3004). Y a continuación se cita el texto de Pablo al que me he referido antes. La formulación del pontífice resulta todavía más explícita, ya que se compromete no solo en general con el conocimiento de Dios a partir de las criaturas, sino de manera expresa con la prueba mediante la causalidad. Se trata, en este caso, del increíble juramento antimodernista, hoy en desuso, que debían pronunciar los teólogos católicos antes de entrar a regentar una cátedra:

$\mathrm{Y}$ en primer lugar, sostengo que Dios, principio y fin de todas las cosas, puede ser conocido con certeza por la luz natural de la razón 'mediante 
las cosas que han sido hechas' [Rom. 1, 20], es decir, por las obras visibles de la creación, como la causa mediante el efecto, y que por lo tanto también puede ser demostrado (Denzinger y Schönmetzer, 1965, p. 3538).

Aunque tales declaraciones no poseen carácter dogmático y fueron redactadas en su momento como defensa en contra de los duros ataques por parte del racionalismo, suelen considerarse como doctrina católica oficial. Sin embargo, muchos teólogos parecen distanciarse hoy de esa posición, y la corriente teológica iniciada por el franciscano Guillermo de Ockham no acepta que los argumentos racionales para demostrar la existencia de Dios tengan carácter concluyente. En el mejor de los casos, pueden considerarse más probables que sus contrarios.

En contra de esta interpretación, que dice no solamente que el teísmo es más probable que el ateísmo, sino que es la única opción realmente racional, existen al menos dos fuertes objeciones, también de carácter teológico, y que han sido muy bien conocidas por la tradición cristiana. Por una parte, y desde la perspectiva de una exégesis del texto bíblico, se señala que el mismo apóstol Pablo anota a continuación que el corazón del hombre se halla oscurecido, de modo que podría entenderse que la razón humana, aunque sea de suyo capaz de conocer a Dios, de hecho no está en condiciones de hacerlo y, de ahí, la necesidad de la revelación divina. Por otra parte, la creencia en Dios ha sido considerada también como un acto de fe, lo que parece implicar que no se puede tratar entonces de una conclusión racional. Y la controversia sobre este punto viene a complicarse cuando no pocos teólogos señalan que el llamado "Dios de los filósofos", es decir, aquel que puede ser conocido por la mera razón, está muy lejos de ser el mismo "Dios de Abraham, de Isaac y de Jacob"3.

\section{El lenguaje religioso}

Emparentada de manera directa con el problema de la racionalidad del teísmo, se halla la cuestión, o las cuestiones, acerca del lenguaje religioso. Las preguntas que se plantean relativas a tal problemática surgen del

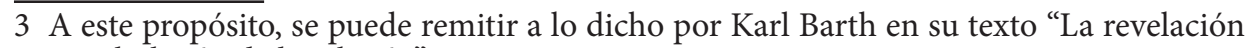
como abolición de la religión". 
llamado "giro lingüístico" que llevó a cabo la reflexión filosófica a partir de los señalamientos hechos por el Círculo de Viena, según los cuales buena parte de los problemas de la filosofía se debían a una errónea comprensión del lenguaje. Así como Descartes había planteado que antes de emprender el estudio de los temas metafísicos era indispensable establecer los alcances de nuestra facultad de conocer, así también vino a decir la Escuela de Viena antes de resolver los problemas que presenta la filosofía, es necesario analizar las condiciones que presenta el lenguaje para su adecuada elaboración.

Mientras que en la discusión sobre el tema dirigió la parada el verificacionismo, exigido por los positivistas más estrictos, el lenguaje religioso tuvo muy poco chance de ser tomado en serio. Porque se consideraba que solo tenían sentido aquellas proposiciones que pudieran ser verificadas de alguna manera mediante la experiencia, y no se ve cómo puedan ser sometidos los enunciados religiosos a las exigencias de una verificación empírica. Sin embargo, no ha faltado quien sostenga que los enunciados religiosos, o al menos un buen número de ellos, son en realidad verificables y, por lo tanto, poseen significado incluso bajo las estrictas exigencias del verificacionismo, solo que su verificación se ve trasladada post mortem. Tal es, por ejemplo, el caso de John Hick en su artículo Teología y verificación (Romerales, 1992, p. 101 y ss.). Aunque su postura pueda resultar a primera vista curiosa, y hasta suscitar una cierta sonrisa, cabe señalar, como lo hace Romerales, "que es así como los creyentes de casi todas las religiones interpretan sus ineludibles asertos escatológicos" (p. 23).

Sin embargo, la vida del verificacionismo estricto fue muy corta y se vio en parte sustituido por la teoría popperiana de la falsación: un enunciado solo tiene carácter científico si puede ser sometido a un proceso de falsación. Fue entonces cuando Anthony Flew enfiló sus baterías contra los enunciados religiosos para mostrar que, aun cuando en realidad son falseables, como por ejemplo en el caso de la existencia del mal, los teístas se las arreglan para reinterpretarlos de tal manera que terminan por no ser falseables, con lo cual pierden todo significado. La existencia del mal en el mundo, viene a decir Flew, es un argumento que demuestra la falsedad de la afirmación acerca de la existencia de un Dios bueno y todopoderoso. Sin embargo, los creyentes terminan diciendo que no podemos en realidad juzgar que ese mal no redunde en un mayor bien, afirmación que, al no 
ser falseable, carece de sentido. Con lo cual nos hallamos en el extremo opuesto al de los defensores de la razonabilidad fuerte del teísmo. Mientras que para estos últimos los argumentos en favor de la existencia de Dios prevalecen contra sus contrarios, Flew se extraña de que los argumentos en contra del teísmo no logren convencer a los creyentes de que sus creencias son irrazonables. A propósito de esto, dice Flew:

Ahora bien, a la personas no religiosas a menudo les parece como si no hubiera un acontecimiento o serie de acontecimientos concebibles cuya ocurrencia llegara a ser admitida por las personas religiosas sofisticadas como una razón suficiente para conceder que "después de todo no había un Dios", o que "Dios realmente no nos ama, pues [...]” (citado en Romerales, 1992, p. 50).

En realidad, los argumentos de Flew no hacen más que retomar el viejo argumento del mal, uno de los tópicos más fuertes y más repetidos en contra de la racionalidad o de la razonabilidad de la creencia en un Dios bueno y todopoderoso. Fue precisamente contra este argumento del mal que Leibniz elaboró su famosa Teodicea. El argumento puede resumirse así: no es posible que los siguientes tres enunciados sea todos verdaderos: a) Dios es omnipotente; b) Dios es bueno; c) existe el mal en el mundo. Ahora bien, como (c) es innegable, entonces hay que negar (a) o (b), o los dos.

E. Tugendhat, por su parte, comparte con S. Freud la idea de que la creencia en Dios es, "no solo un error, sino algo peor: una ilusión. Y una ilusión es para Freud una creencia que consiste en la proyección de un deseo", a lo cual añade:

La idea de un ser espiritual y moral que existía antes de la evolución biológica e incluso por fuera del espacio y del tiempo es tan poco compatible con nuestra manera de ver la realidad, que las concepciones religiosas tendrían que ser abandonadas aun si no tuviéramos el argumento ideológico de Freud. Esto parece ser una obligación de honestidad intelectual (2001, pp. 13-14).

Pero, cuando se observa que los argumentos contra el teísmo no parecen conmover a los creyentes, bien puede uno preguntarse, como lo 
hizo Ludwig Wittgenstein, si el hecho de que las doctrinas religiosas no parezcan tener un significado fáctico, implica necesariamente que carezcan de todo significado. No, responde Wittgenstein: las doctrinas religiosas son juegos de lenguaje que desempeñan papeles muy importantes, diversos de las funciones cognoscitivas. Despiertan, por ejemplo, sentimientos morales muy elevados, promueven actitudes emocionales de gran significación, sustentan conductas ejemplares y, en fin, desempeñan toda una gama muy variada de tareas que las hacen merecedoras de todo nuestro reconocimiento y nuestro respeto.

Mucho se ha escrito acerca de lo dicho por Wittgenstein sobre la religión, y no sería tarea fácil resumir los argumentos y contrargumentos que se han esgrimido a este respecto. Podríamos, sí, decir que alrededor de esas pocas líneas ha girado, en los últimos años, una parte nada despreciable de las discusiones acerca de la filosofía de la religión. La interpretación wittgensteiniana de la religión pareciera ofrecer varias ventajas. Por una parte, se le otorga al fenómeno religioso una gran respetabilidad, al descartar la posibilidad de declarar irracionales o insensatos a los creyentes. Por la otra, se libra a la religión de tener que estar justificando sus aserciones, al descartar de un plumazo la teología. Además, se insiste en la tarea religiosa de moralización, al margen de cualquier pretensión dogmática, pero sin desautorizar por ello a las doctrinas religiosas, ya que son juegos de lenguaje que sirven de vehículo a sentimientos y actitudes muy respetables.

Por supuesto que los teólogos no suelen mostrar, por lo general, mayor interés por esta clase de ofertas. Sin embargo, las críticas no han provenido exclusivamente dela teología. En realidad, la interpretación wittgensteiniana de la religión presenta serios inconvenientes. Si su pretensión no es decirnos cómo debe ser la religión o qué es lo que en realidad hacen los creyentes aunque no lo sepan, sino describirnos, de manera adecuada, lo que ocurre en realidad con quienes comparten una fe religiosa, habría que comenzar por decir que los creyentes no parecen reconocerse en esa descripción. Porque, en primer lugar, no resulta claro si la religión en general es un solo juego de lenguaje, o si hay tantos juegos de lenguaje como religiones; más aún, tantos como clases de creyentes. Porque, dentro de una religión en particular, es muy distinta la manera como ella es vivida o comprendida por un místico, o por un monje, o por un teólogo, o por un hombre 
religiosamente cultivado, o por una persona ignorante. Pero además, lo que pretende la mayoría de los creyentes con sus aserciones religiosas no es solo cultivar actitudes o despertar sentimientos, sino hacer aseveraciones sobre realidades que ellos consideran existentes con independencia de tales aseveraciones. Esto hace que, sobre este fideísmo à la Wittgenstein, llegue a decirnos Romerales: "Si la religión que hay que defender (o apuntalar) es la que tiene en mente Wittgenstein, más vale hundirse con toda dignidad, que mantener a flote un espectro viviente, reconfortándonos diciendo que "ésta es la religión más [de]pura[da] y genuina”" (1992, p. 35).

No voy a detenerme a examinar si esas interpretaciones corresponden a las verdaderas intenciones de Wittgenstein, y si sus observaciones sobre la religión como juego de lenguaje pueden llegar a ser compatibles con la concepción religiosa del cristianismo, sobre lo cual he tenido ocasión de expresarme en otro contexto ${ }^{4}$. Voy a traer más bien a consideración una postura que se asemeja mucho a la de Wittgenstein y es conocida hoy con el nombre de "epistemología reformada", cuyo principal intérprete ha sido el filósofo norteamericano Alvin Plantinga. Recordemos que con el nombre de "reformados" se hace referencia a la corriente calvinista dentro del protestantismo. Se trata, entonces, de un grupo de pensadores de origen calvinista que ha reflexionado sobre la religión desde la perspectiva de la epistemología contemporánea.

Al retomar algunos aspectos de la teología calvinista, estos filósofos comienzan por atacar duramente el llamado "fundacionalismo", es decir, la idea de que solo podemos aceptar como razonables aquellas creencias que poseen un fundamento en la evidencia. No se trata, sin embargo, de rechazar la necesidad misma de una fundamentación, sino de rechazar la exigencia de que tal fundamentación tenga que ser, en último término, una evidencia. La creencia en Dios, viene a decirnos Plantinga, en cuanto es una creencia básica, no necesita ella misma de una razón o de una evidencia, porque ella es precisamente el fundamento de la creencia que tenemos en la razón o en la evidencia. Tesis que tiene unas claras resonancias tanto anti-cartesianas como nominalistas.

A diferencia del fideísmo à la Wittgenstein, los reformados no consideran que la teología natural malinterprete a la religión al buscar

4 Ver el artículo “Wittgenstein y la religión”. 
un fundamento racional para la creencia. Es cierto que ellos consideran esa teología como innecesaria para la fe, pero no por ello deja de tener una cierta utilidad. Porque lo único que necesita la fe es que no se pueda demostrar la irracionalidad de sus creencias. Es cierto, como lo ha señalado Tugendhat, que el solo hecho de que la creencia en Dios no pueda ser refutada, no constituye de por sí un argumento en su favor (2001, p. 14). El mismo Plantinga ha dedicado no pocos esfuerzos a la tarea de desarticular las argumentaciones que buscan demostrar la irracionalidad del teísmo. Con esto retoman un tópico importante de la teología cristiana tradicional, ya que, según buena parte de esa tradición, las verdades de la fe escapan por su naturaleza a la comprensión racional, en el sentido de que la razón humana no está en condiciones de juzgarlas. Esto no significa, como pretendía S. Kierkegaard, que sean irracionales. Pero tampoco puede demostrarse que no lo sean. Para que el creyente pueda aceptarlas basta que hayan sido reveladas por la palabra de Dios y que no se pueda demostrar que son irracionales.

Por lo demás, ambos aspectos resultan inseparables. Porque si una doctrina no ha sido revelada por Dios, no puede ser objeto de fe religiosa; pero si pudiera llegar a probarse que esa doctrina es abiertamente contraria a la razón, no podría haber sido revelada por Dios. Ahora bien, en cuanto a que una verdad racional, es decir, accesible a la razón por la sola fuerza de su luz natural, pueda o no ser objeto de una revelación divina, es, como ya dijimos, una cuestión controvertida. Y tal es precisamente el caso de la existencia de Dios, que algunos consideran, con Tomás de Aquino, tanto una verdad accesible a la sola razón como una verdad revelada. Todo esto, por supuesto, no deja de presentar problemas para cuya solución han desplegado, tanto los teólogos como los filósofos teístas, toda su agudeza.

Vale recordar que un expediente semejante fue utilizado por I. Kant para despejarle el campo a su fe filosófica, partiendo del problema de la libertad humana. Su argumento puede resumirse así: como no resulta posible demostrar que la realidad en sí misma tenga que obedecer a las leyes de la necesidad causal propias de nuestro entendimiento, no se puede rechazar como irracional el convencimiento que tenemos de ser libres. Es cierto que el libre albedrío choca de frente con la necesidad causal, pero esta solo rige para los fenómenos, es decir, para nuestra manera de conocer 
el mundo. En cuanto al mundo nouménico, es decir, el mundo en sí mismo, no solamente no lo sabemos, sino que estamos en condiciones de mostrar por qué no podemos saberlo.

No creo necesario señalar las numerosas críticas de que han sido objeto estos planteamientos de la epistemología reformada, tanto por parte de los ateos como de muchos teístas. Por lo demás, algunos consideran que liberar a las creencias religiosas de su obligación de justificarse racionalmente resulta un expediente peligroso, ya que le abre las puertas a todo género de creencias. Además, contra lo que pensaba Calvino y sostienen sus continuadores, no es fácil aceptar que el hombre posea por naturaleza un sentido interno de la presencia divina. La experiencia no parece confirmar esa doctrina. Pero, sobre todo, sustraer a la religión de los dictados de la razón resulta una empresa muy discutible. Romerales lo señala con claridad:

En fin, creo que la religión no puede ni debe sustraerse al dictamen de la razón. En este sentido, considero la teología filosófica como inexcusable para cualquier filósofo dela religión, y aun para cualquier creyente ilustrado. Y, me atrevería a decir, hasta para cualquier agnóstico o ateo: porque no es menos importante justificar racionalmente la creencia que la increencia. (1992, p. 43).

Cabe, sin embargo, preguntarse hasta qué punto los epistemólogos reformados llevan su distanciamiento frente a las exigencias de la razón. Porque una cosa es liberar a la fe de tener que justificar racionalmente sus creencias, y otra muy distinta decir que se pueda creer aquello que resulta, a todas luces, irracional.

Hemos podido ver cómo el panorama de la filosofía de la religión se muestra hoy lleno de interesantes perspectivas, y objeto de una constante y muy viva controversia. Por lo demás, conviene tener en cuenta que esta controversia comienza a interesarse cada vez más por muchas de las tesis que fueron sustentadas a lo largo de la historia cultural de Occidente por teólogos o filósofos tanto cristianos como musulmanes o judíos. La rica tradición medieval está siendo estudiada a la luz de la conceptualización moderna. Porque no podemos olvidar que casi todos los problemas que son hoy objeto de interés fueron de alguna manera considerados en su momento y elaborados con los instrumentos conceptuales disponibles. Las diversas tendencias platónicas o aristotélicas, las grandes controversias 
entre las escuelas, la tensión entre las verdades de la fe y la verdades de la razón, la confrontación con el pensamiento pagano, la autonomía relativa, pero no por ello menos efectiva, de la razón humana frente a las enseñanzas de la fe y la autoridad de la Iglesia, en fin, todas esas grandes quaestiones disputatae, vuelven a ser objeto de atención y fuente de inspiración filosófica. Después de todo, la religión puede ser practicada, defendida, abandonada o rechazada, pero difícilmente se la puede ignorar. 


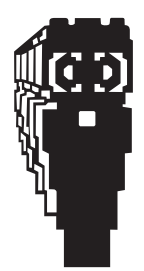

